Third World Science : continuing our review of science in developing countries, we look at an Indian success

story (below) and the economic and political situation facing a scientist in Ghana (overleaf)

\title{
Blue-green algae to fertilise Indian rice paddies
}

The use of chemical fertilisers can be reduced by a third if algae are applied to rice paddies, writes Anil Agarwal

Sclentists of the Indian Agricultural Research Institute in New Delhi are actively promoting the use of bluegreen algae as a biological method of fixing nitrogen in rice fields. Dr G. S. Venkataraman of IARI has collected a bank of useful strains of blue-green algae from Indian rice fields. Extensive field trials have been carried out in various parts of India to study the effect of inoculating certain strains of blue-green algae on grain yields of high-yielding rice varieties responsive to inputs of nitrogen.

These experiments reveal that:

- in the total absence of chemical fertilisers, application of blue-green algae can fix about $25-30 \mathrm{~kg}$ of nitrogen per hectare per cropping season producing a $10-15 \%$ increase in grain yield;

- where chemical fertilisers are used, their dose can be reduced by about one-third and supplemented by bluegreen algae to get the same grain yield;

- even when the full recommended levels of chemical fertilisers are used, complementation of blue-green algae is beneficial resulting in higher grain yields.

The increase in yields in experiments conducted by the IARI ranged from 2 to $29 \%$ with an average of $7.2 \%$. Besides nitrogen, it seems blue-green algae can also provide crop plants with many useful organic growth substances and vitamins.

The IARI scientists have found that blue-green algae can establish themselves almost permanently in a farmer's field if inoculation is done repeatedly for 3-4 cropping seasons. This prod:ces an appreciable population buildup and no further inoculation is needed in subsequent years, unless some very unfavourable ecological conditions intervene.

The blue-green algae technology is cheap and, therefore, extremely relevant for poor rice farmers for whom the high cost of chemical fertilisers poses a serious constraint in adopting high-yielding varieties. This problem is considered to be an important reason for the slow spread of the green revolution to rice. Most Indian rice farmers are much poorer than the wheat farmers of northern India who have rapidly adopted the green revolution package of practices.

Eighty-seven per cent of the rice area in India consists of holdings of
1-4 hectares and the rest consists of holdings of less than one hectare. Yet rice farmers account for the biggest share of chemical fertilisers used in the country. Rice is the most important and extensively grown cereal in India covering over 38 million hectares.

Emphasising the importance of bluegreen algae under these socio-economic conditions, Dr H. K. Jain, IARI's director points out that "if one-third of the nitrogen requirement of the rice crop in many parts of India could be met through the use of blue-green algae, a major constraint in increasing production of this most important cereal will have been overcome".

The IARI estimates that while 25 $\mathrm{kg}$ of nitrogen would cost about Rs 100 (approxmately $f 6$ ), the algal material required to provide the same amount of nitrogen to the farmer's field would cost just about Rs 30 (£2), even if it were produced commercially. But if the farmer were to produce his own material the cost could fall to Rs 7 $(50 \mathrm{p})$ or even less.

Blue-green algae can be easily produced in any village. The farmer first has to make a simple pit. This could be made of galvanised iron sheets or brick and mortar or by simply digging the earth and lining it with a polythene sheet to hold water. Ten kilograms of soil mixed with $200 \mathrm{gm}$ of ammonium superphosphate is placed in this pit, and the pit filled with 2-6 inches of water. When the soil has settled down, sawdust and the starter culture-a soil based mixture of Aulosira, Tolypothrix, Nostoc, Anabaena and Plectonema-is sprinkled on the pit. Packets of the starter culture are being sold by the IARI for just Rs $2.50(15 \mathrm{p})$ each.

The pit must be kept exposed to the Sun and water added daily to it if the rate of evaporation is high. In hot summer months, a thick algal mat can be obtained within a week. The farmer can then allow the water to evaporate and the algae to dry up into thick flakes, which he can store in bags for future use in fields.

This Sun-dried algal material can be stored for long periods and used both directly in the field as well as a starter culture for producing more algae. In the fields, the algae should be applied at the rate of $10 \mathrm{~kg}$ hectare one week after transplantation and the field kept waterlogged for at least a couple of days after algal application. Pest control measures do not interfere with the establishment of the algae, according to IARI scientists.

Several Indian States like Tamil Nadu, Andhra Pradesh, Kerala, Karnataka, Madhya Pradesh and Maharastra are now taking an active interest in this algal biofertiliser. The department of agriculture of Tamil Nadu, which has taken maximum interest uptil now, has included algal complementation in the package of practices it recommends to rice farmers. Farmers are being motivated to use blue-green algae through the mass media and attractive hoardings in villages. Large-scale algal production is being undertaken by paddy experiment stations, state seed farmers, panchayat unions (village councils), and individual farmers.

Interest in blue-green algae has also spread to Burma, Sri Lanka, Bangladesh and Nepal. These countries were recently visited by Dr G. S. Venkataraman on behalf of the Food and Agriculture Organisation to conduct a training course in the production and use of algal biofertilisers. The technology developed in India has been found to be reproducible in some of these countries and algal production has been successfully started by scientists in Burma.

There is still considerable scope for further research in this field. IARI scientists have found, for instance, certain areas in India, like the green revolution region of Punjab, where the inoculated algae do not establish well. Antagonistic indigeneous microflora in the soil and other factors seem to play a role but further elucidation is needed.

Dr H. K. Jain also points out that the Chinese and Vietnamese have tried to use the Azolla fern to provide biological nitrogen in rice fields instead of blue-green algae. A critical evaluation of the relative merits of the two biological systems under different agroclimatic situations would be useful.

The work on blue-green algae is a part of the All-India Co-ordinated Project on Algae sponsored by the Government of India's Department of Science and Technology in New Delhi. Seven Indian research institutes are looking at various uses of different types of algae like fermentation of marine algae to produce methane in bio-gas plants, production of protein rich algae suitable for human or animal feed and for applications such as sewage reclamation. 